\title{
Patient Safety Culture from the Viewpoint of Nurses: A Cross-Sectional Study in 2016
}

\author{
Seyed Ali Majidi *1, Shiva Alizadeh ${ }^{2}$, Sobhaneh kouchakzadeh Talami ${ }^{3}$, Hamideh \\ Safarmohammadi ${ }^{4}$, Ehsan Kazemnezhad Leily ${ }^{5}$, Monika Motagi ${ }^{6}$, Mehdi Barzegar ${ }^{7}$
}

1. Department of Nursing \& Midwifery, Rasht Branch, Islamic Azad University, Rasht, Iran.

2. Department of Nursing \& Midwifery, Rasht Branch, Islamic Azad University, Rasht, Iran.

3. Department of Nursing \& Midwifery, Rasht Branch, Islamic Azad University, Rasht, Iran.

4. Poursina Education \& Treatment Center, Guilan University of Medical Sciences, Rasht, Iran.

5. Guilan Road Trauma Research center, Guilan University of Medical Sciences, Rasht, Iran.

6. Kashan University of Medical Sciences, Kashan,Iran.

7. Hazrat-e Rasool general Hospital, Iran University of Medical Sciences (IUMS), Tehran, Iran.

*Correspondence: Department of Nursing \& Midwifery, Rasht Branch, Islamic Azad University, Rasht, Iran. Tel: +98-9111388840. Email: salimajidi@gmail.com

Received Jun 27, 2019; Accepted Jun 28, 2019

\section{Abstract}

Background: Patient safety is one of the main components of the health care services quality that implies avoidance of any harm or damage to the patient during the delivery of health care. The purpose of this study was to determine the patient safety culture from the view point of nurses in the hospitals of Guilan province in 2016.

Methods: This cross-sectional study was done on 400 nurses from the nurse community in Guilan province, Iran in 2016. The sampling was performed as the two-stage cluster sampling method. Data were collected using a modified questionnaire based on the Hospital Survey on Patient Safety Culture (HSOPSC). Data were presented with descriptive statistics analysis using in SPSS-14. The significant level was considered less than 0.05 .

Results: Most of the nurses were female (89\%), with a mean age of $34.28 \pm 6.86$ years. The most response to the items was related to "Please give your work area/unit in this hospital an overall grade on patient safety" that was the acceptable option (47.5\%). The mean score of the patient safety was $3.28 \pm 0.86$.

Conclusions: The results showed two dimensions including staffing and teamwork within units. 
Feedback and communication about errors were the most important dimensions of the patient safety culture. Accordingly, it should be noted that paying more attention to the patient safety culture can lead to improve hospital condition levels.

Keywords: Hospital, Nurses, Patient safety, Safety culture 10.29252/jgbfnm.16.2.61

\section{Introduction}

One of the most prominent rights of human beings is safety from harms and damages when they are receiving health services. The patient safety is one of the main components of the health care services quality that implies avoidance of any harm or damage to the patient during the delivery of health care and curing (1). Despite growing advances in health care domain, the patient safety is still a warning issue in the health care systems worldwide (2). However, medical errors are one of the five common causes of death all around the world. The World Health Organization estimates that every year, more than ten million patients fall victim to harms and deaths that are resulted from unsafe care and medical activities round the world. (3).In this regard, many efforts have been made to improve patient safety so that we can provide alternative ways for proper reactions with respect to the problems and resolve them before taking place. Therefore, efforts to identify and eliminate harms before they occur will lead to a high potential which can significantly improve the safety (4). The safety in an organization will become worthwhile and a priority if all the individuals in the organization discover its importance and internalize it (5).Culture is one of the four fundamental components of each organization and is defined as a set of perceptions, cognitions, and awareness of a particular group whose members have their own cognitive, emotional and behavioral elements. The safety culture is the production of values, attitudes, perceptions, merits, individual behavior patterns, and group behavior patterns that determine the commitment, methodology, and efficiency of the health organization (6). At present, the patient safety leaders are proposing the safety culture as one of the primary and essential components of health care organizations to promote and improve patient safety (7). The key components of the patient safety culture include: the common belief that health care responsibility is high-risk, organizational commitment to detect and analyze mistakes and harms to the patient, and ultimately to create conditions that strike a balance between the demand for reporting errors and disciplinary actions (8).Achieving safety culture depends on a proper understanding of the subject that "values, beliefs, and norms" are of importance for the organization, and each of the attitudes and behaviors are expected to regard the patient safety (9). An organization will be of safety culture if it accepts the high-risk nature of health care services, therefore it tries to provide conditions in which it is permitted to individuals to report error and close to error cases freely and without fear of punishment (10). A review study was performed by the "Foundation for Health in England" about the relationship between safety culture and corresponding events to patient, the results showed that there is a direct correlation between the safety culture and reduction of undesirable events, medication errors, length of hospital remaining, readmission, and disease (11). The indices of a powerful safety culture include: management commitment to learn from the mistakes, to encourage and to practice teamwork, to identify potential risks, using a system of reporting and analyzing adverse events occurred at the hospital in relation to patient safety, and assessment of patient safety culture among staff (12). In 
units where the patient safety culture is below the standard levels, mistakes will also occur more often (13).A positive safety culture can encourage the health care providers to report errors and analyze them, which in turn will be an effective tool to improve the safety. The first step to create the positive safety culture is assessment of the current safety culture (14). Carrying out precautions of the safety without an appropriate assessment can increase costs and create new and unexpected risks (15). The assessment of the organization's safety culture makes it possible to obtain a clear viewpoint of the patient's safety aspects that require more attention; this in turn will allow the managers of hospitals to identify the strengths and weaknesses of their safety culture and patient safety issues (16).With respect to the significance of hospital officials` awareness of current state of patient safety culture and identifying solutions to improve and promote it, and in relation to the nursing service providers at the forefront of hospitals and their special role in providing health services to patients, the aim of the present study was to determine the patient safety culture in the viewpoint of nurses in Guilan province.

\section{Methods}

This cross-sectional study was done on nurses from the nurse community in Guilan province in Iran. Following the ethical approve, 400 nurses who agreed to participate in the study signed a written informed consent. They were assured of the confidentiality of their private information and volunteering for participation. Data were gathered during four months, since March 2016. The study population comprised all the nurses working in the hospitals of Guilan province in the north of Iran. The sampling method was a two-stage cluster. In the first step, the lists of the cities, units of the hospitals, as well as the number of staff members were determined. Due to the large number of the employed nursing staff throughout the hospitals of the province, 10 cities were randomly selected based on the random numbers (the city was considered as a cluster). According to the number of the nurses in each city, the suitable proportion of employed nurses, 40 people per cluster, was selected randomly. Then, in the selected hospitals, sampling was randomly performed in all of the three shifts according to the number of the employed nurses.

To collect the data, the "Hospital Survey on Patient Safety Culture (HSOPSC)" questionnaire was used. The HSOPSC developed by the Agency for Healthcare Research and Quality (17). This questionnaire was translated and modified to suit with the Iranian population. So far, several studies have used this questionnaire to assess the safety in the United States and other countries (18).

The original version of questionnaire (2010) was designed to assess 12 dimensions of health care with 42 items of patient safety culture. All items of the HSOPSC questionnaire were developed based on the 5-point Liker response scale of the agreement, with 5 representing 'Strongly agree', and 1 denoting "strongly disagree, or with the help of frequencies (e.g. "Never" to "Always"). The different dimensions of the questionnaire included:

- Teamwork within units (4 items)

- Supervisor / manager expectations and actions promoting safety (4 items)

- Organizational learning-continuous improvement (3 items) 
- Hospital management support for patient safety (3items)

- Overall perceptions of safety (4 items)

- Feedback and communication about error (3items)

- Communication openness (3 items)

- Frequency of event reporting ( 3 items)

- Teamwork across units (4 items)

- Staffing (4 items)

- Hospital handoffs and transitions (4 items)

- Non-punitive response to error (3 items)

In this study and for more reliability, the validity and reliability of the questionnaire were evaluated. To determine the validity, the questionnaire was presented to 10 experts in the field of nursing and research. The Content Validity Index (CVI) was calculated 85\% and the Content Validity Ratio (CVR) was computed more than 90\%. Reliability of the questionnaire was calculated $89 \%$ using internal correlation coefficient (Cronbach's alpha).Data were analyzed using SPSS version 14.0 (IBM, USA). Data are presented as mean values \pm SD and frequency. Normal data distribution was examined using Kolmogorov-Smirnov test.using Mann-Whitney, Friedman and Kruskal Wallis test. Significant level $<0.05$ was considered. Factor analysis was used to determine the most important domain of the patient safety culture by exploratory method.

\section{Results}

The findings showed that the mean age of the participants was $34.28( \pm 6.86)$. The majority of the participants were female (89\%), holding bachelor degrees (93\%). In terms of employment status, the lion`s share of the nurses (20\%) were employed in the emergency department. (Table 1)

Table 1. Sociodemographic characteristics of the Nurses $(n=400)$

\begin{tabular}{|l|l|c|c|}
\hline \multirow{2}{*}{ Gender } & Male & N & \% \\
\cline { 2 - 4 } & Female & 44 & 11.0 \\
\hline \multirow{3}{*}{$\begin{array}{c}\text { Age } \\
\text { Year) }\end{array}$} & Less then 30 & 356 & 89.0 \\
\cline { 2 - 4 } & $30-39$ & 116 & 29.0 \\
\cline { 2 - 4 } & More then 39 & 176 & 44.0 \\
\hline Ward & Medicine (non-surgical) & 108 & 27.0 \\
\cline { 2 - 4 } & Surgical & 44 & 11.0 \\
\cline { 2 - 4 } & Obstetrics & 56 & 14.0 \\
\cline { 2 - 4 } & Pediatrics & 50 & 12.5 \\
\cline { 2 - 4 } & Emergency department & 62 & 15.5 \\
\cline { 2 - 4 } & Intensive care unit & 80 & 20.0 \\
\cline { 2 - 4 } & Nursing office & 58 & 14.5 \\
\hline
\end{tabular}


With regards to the working experience of the studied samples, the mean and standard deviation of the length of employment in clinical areas were years, and the mean and standard deviation of the duration of working in the current hospital were. The mean and standard deviation of the working hours per week and the duration of working in current specialty or profession were hours, and per year respectively. (Table 2)

Table 2. Professional characteristics of the Nurses $(n=400)$

\begin{tabular}{|l|c|c|c|c|}
\hline & Minimum & Maximum & Mean & $\begin{array}{c}\text { Std. Devia- } \\
\text { tion }\end{array}$ \\
\hline $\begin{array}{l}\text { length of employment in clinical areas } \\
\text { (Year) }\end{array}$ & 1.00 & 27.00 & 7.72 & 5.15 \\
\hline $\begin{array}{l}\text { Duration of working in the current hospital } \\
\text { (Year) }\end{array}$ & 1.00 & 20.00 & 5.87 & 4.24 \\
\hline Working hours per week & 12.00 & 113.72 & 62.86 & 26.23 \\
\hline $\begin{array}{l}\text { Duration of working in current specialty or } \\
\text { profession (Year) }\end{array}$ & 1.00 & 19.84 & 10.42 & 7.93 \\
\hline
\end{tabular}

Factor Analysis was used to determine the most important dimension of the patient safety culture questionnaire by exploratory method. Based on the Communalities Index, the "Staffing (0.790)", "Teamwork within units (0.772)" and "Feedback \& communication about error (0.748)", with the highest loading respectively, were recognized as the most important dimensions of the patient safety culture questionnaire. In examining the different dimensions of the patient safety culture questionnaire, the highest and lowest means in terms of ranking were determined. (Table 3)

Table 3. The primary shared of the difference dimensions of the patient safety

\begin{tabular}{|l|c|c|}
\hline \multicolumn{1}{|c|}{ Communalities } & Initial & Extraction \\
\hline Teamwork within units & 1.000 & .772 \\
\hline Supervisor/manager expectations \& actions promoting patient safety & 1.000 & .309 \\
\hline Organizational learning_continuous improvement & 1.000 & .707 \\
\hline Management support for patient safety & 1.000 & .587 \\
\hline Overall perceptions of patient safety & 1.000 & .600 \\
\hline Feedback \& communication about error & 1.000 & .748 \\
\hline Communication openness & 1.000 & .518 \\
\hline Frequency of events reported & 1.000 & .672 \\
\hline Teamwork across units & 1.000 & .610 \\
\hline Staffing & 1.000 & .790 \\
\hline Handoffs \& transitions & 1.000 & .546 \\
\hline Nonpunitive response to errors & 1.000 & .718 \\
\hline
\end{tabular}

The most prevalent response to the studying items was related to this term, "Please give your work area/unit in this hospital an overall grade on patient safety" that was the acceptable option 
(47.5\%). Moreover, the mean and standard deviation in the whole of the patient safety domain and in the range of 1 to 5 was equal to . Over and about that, the most common response to the studying items was related to the term, "In the past 12 months, how many event reports have you filled out and submitted?", in which three to five incidents was mentioned (31\%). In examining the correlation coefficient of the samples` working experience terms, with dimensions of patient safety culture and based on Friedman test, there was a significant and negative correlation between this term, "How long have you worked in your current hospital work area/unit" and these dimensions, "Teamwork within units $(\mathrm{r}=0.173$ and $\mathrm{p}<0.014)$, Feedback $\&$ communication about error $(r=0.215, p<0.002)$, communication openness $(r=0.175, p<0.013)$, Frequency of events reported $(r=0.206$ and $P<0.003)$, Staffing $(r=0.227, p<0.001)$ and non-punitive response to errors $(\mathrm{r}=0.144$ and $\mathrm{P}<0.042)$ ". A comparative study analysis on the scores of the dimensions of the patient safety culture, according to the hospitalized part of the patient and based on Kruskal-Wallis test showed that there is a significant difference in the following dimensions: "teamwork across units $(\mathrm{p}<0.0001)$, supervisor / manager expectations and actions promoting patient safety $(\mathrm{p}<0.0001)$, organizational learning-continuous improvement $(\mathrm{p}<$ 0.007), management support for patient safety $(\mathrm{p}<0.033)$, feedback \& communication about error $(p<0.001)$, communication openness $(p<0.003)$, frequency of events reported $(p<0.001)$, staffing ( $<<0.0001)$, and non-punitive response to errors $(\mathrm{p}<0.003)$ ". Therefore, that, in these dimensions, including "teamwork across units, supervisor / manager expectations \& actions, organizational learning-continuous improvement, management support for patient safety, feedback \& communication on error and communication openness", the obstetrics department was considered as the most important part of in the different dimensions of the patient safety culture. Moreover, as for the dimensions "non-punitive responses to errors, and staffing and teamwork across units", the nursing office was considered as the most important part in the different dimensions of the patient safety culture. A comparative study analysis on the dimension scores of the patient safety culture in terms of employment status and based on Kruskal-Wallis test showed that in "teamwork within units $(\mathrm{p}<0.002)$, supervisor / manager expectations and actions promoting patient safety $(\mathrm{p}<0.005)$, overall perceptions of patient safety $(\mathrm{p}<0.036)$, staffing $(\mathrm{p}<0.045)$ and handoffs \& transitions $(\mathrm{p}<0.045)$ " dimensions, there was a significant difference. Such that, in the "Teamwork within units, supervisor / manager expectations and actions promoting patient safety, and staffing" dimensions, official staff were considered as the most important occupation in the mentioned dimensions. Also, in the "Overall perceptions of patient safety, and Handoffs \& transitions" dimensions, probationer staff were considered as the most important occupational category in the patient safety culture. Comparing the dimensions scores of the patient safety culture regarding the age and based on the Kruskal-Wallis test illustrated that there is no significant difference between the different domains of patient safety culture in terms of age in the different units under study. On the other hand, juxtaposing the different domains'scores of the patient safety culture in relation to the sex and according to Kruskal-Wallis test showed that in the dimensions of "teamwork within units $(p<0.002)$, supervisor / manager expectations and actions promoting patient safety $(\mathrm{p}<0.005)$, overall perceptions of patient safety $(p>0.036)$, staffing $(p<0.045)$ and non-punitive response to errors $(p<0.045)$ " there was a significant difference, such that, the safety culture of men, in the mentioned dimensions, was found to be higher than women. 


\section{Discussion}

According to the research findings, the dimensions of "staffing, teamwork within units, and feedback \& communication about errors" were the most important dimensions of the patient safety culture. Researches showed that major catastrophes occur in organizations where there is not sufficient number of employees (19), and there is not a strong link between the availability of health care providers and the health outcomes of the population. Lack of staff numbers and their experience can reduce the ability of the organization to provide health care (20). Also, the researchers showed that "teamwork within units and organizational learning and continuous improvement" were the dimensions allocated the highest levels of patient safety culture $(21,22)$. Another study on the patient safety culture shows that in the emergency unites, "teamwork within units" and "communication Openness" are the most important dimensions (23). Assessments from a similar study demonstrate the results were similar to the recent study,_in which the "Teamwork within unit" has allocated the highest score among the patient safety culture dimensions (24).Regarding errors, researches showed that if employees do not interact with each other about the errors occurring in the department and hide the errors, the individuals will not be aware of the errors and able to provide a solution to prevent re-occurring of the errors, consequently, operational program of the staff will not change (25).In examining the viewpoints of the samples concerning the phrases of the safety culture questionnaire in the dimension of, "teamwork within units", the highest mean in the terms ranking was related to the term, "In this unit, people treated each other with respect". Mutual respect is one of the most substantial factors that affect the performance of the hospital departments. Regarding mutual respect, the employees of the departments should always respect the colleagues and pay attention to the importance of their role in the department. (20). Mutual respect among employees is one of the most important factors in achieving the organizational goals (26). Through cooperation and teamwork, it is possible to use the resources and increase productivity. Furthermore, the staff of the departments, while they carry out care as a group, will experience a whole lot in patient care, and as a result, the efficiency of the department will increase (27). The desire to receive help and assistance from colleagues, if necessary, is an effective factor in teamwork (20), which, in turn, can increase the safety culture of the patient. In "supervisor / manager expectations \& actions promoting patient safety" dimension, the highest mean ranking was related to the term "My supervisor/manager overlooks patient safety problems that happen over and over". The director of the department, for the implementation of patient care programs, should devote enough time to consult and discuss with the staff, and in the event of an incident in the department, the director ought to devote some time to discuss about the problems and to remove the existing barriers. The leadership style of the department director will be more effective when the director behaviors proportionally with group members (28).Regarding the "organizational learning-continuous improvement" dimension, the highest mean ranking pertained to the phrase, "After we make changes to improve patient safety, we evaluated their effectiveness". Increasing the scientific and practical skills of the hospital department's staff prevents mistakes and harms to the patient (29). Increasing the knowledge of the staff in the patient safety domain should be considered as one of the most important priorities in the departments $(30,31)$.In the " management support for patient safety" dimension, the highest mean ranking, was affiliated to "Hospital management provides a work climate that promotes patient safety" term. Important features of the safety culture can be alluded through the existence of an error reporting system, utilization of a data reporting system to improve processes, reducing blames of the individuals, 
teamwork, reduction of errors covering, proper communication between colleagues to improve patient recovery, and organization management and training the staff about safety culture (32). As for the dimension of "feedback \& communication about error", the highest mean ranking was related to the term, "We are informed about the errors that happen in this unit". The existence of an appropriate and regularly individual and group feedback among the staff of departments leads to success in providing care to patients (33). Furthermore, after an incident occurs in the department, the director of the department should devote enough time to discuss and prevent that from happening again (34).In respect of "communication openness", the highest mean ranking was connected to the term, "Staff are afraid to ask questions when something does not seem right". Hospital staff should be aware of the errors that occur in the department. They can easily ask the individuals at higher levels about the decisions and actions of the department just in case and also can freely speak on issues that may have a negative impact on the patient care (35).Concerning the dimension "teamwork across units", the highest mean ranking was influenced by the term "It was often unpleasant to work with the staff from other hospital units". Increasing the staff awareness of promoting patient safety is believed to be as one of the most important priorities (30), therefore the number of staff members should be sufficient in different shifts for admission and providing services (36). If the staff do not interact with each other about the errors occurring in the department and hide them, the individuals will not get aware of the errors and consequently will not provide a solution to prevent them from occurring recurrently. Subsequently, the staff operational plan will not change (37).Respecting the dimension "frequency of events reported", the highest mean ranking was allied to the term, "How often is a mistake which is thoroughly caught and corrected before affecting the patient reported? When a mistake is made, but it is caught and corrected before affecting the patient, how often is this reported". Reporting and collecting information systematically, creating conditions free from blaming individuals, committing management for safety, and providing focus on systems and working processes in the hospital instead of focusing on individuals are factors found to be of high significance in enhancing and promoting the safety culture (38). With reference to the dimension "handoffs \& transition", the highest mean ranking was linked to the term, "Important patient care information is often lost during shift changes". The development of patient-related safety performance criteria is essential for clinical and administrative staff in the hospital, accordingly appropriate training sessions should be held on the main concepts of the patient safety for the hospital staff (39).In regard to the dimension "non-punitive response to errors", the highest mean ranking was related to the term, "Staff worry that mistakes they make are kept in their personnel file". Different department's staff in the hospital should discuss the problems and interact with each other on best solutions to prevent mistakes (40). Department's staff should have the ability to manage conflicts in the parts of their service independently (41). Blaming individuals leads to the loss of learning opportunities from mistakes and prevents both better training for the care providers regarding their functions and alertness related to the situations where the risk of error is high. On the other hand, blaming individuals prevents them from improving and creating effective systems and efficient processes which in turn can impede committing similar errors in the future. One of the biggest obstacles to preventing the mistakes is punishing and blaming individuals for their mistakes (42).According to the findings, the most commonly reported response to the patient safety issue in "your work area / unit" was the acceptable option. Unlike to recent research results, in another study, the score of the patient safety culture was in the low-grade and low-end (43). In the recent study, the most commonly reported response, from the studying samples in the past 12 months, was reported via three to 
five incidents. That was because the nurses believed that the errors report would be used against them due to being recorded and kept in their personnel files, consequently for the sake of the fear of punishment, the frequency of the errors reporting was low so that in the past 12 months there was no history of reporting any errors (41). If the errors are not reported, there will be found no possibility of eliminating the root cause of their occurrence in order to prevent the re-occurrence. In other studies, the frequency of error reporting dimension and non-responsive responses belongs to the weak points of patient safety culture and showed the lowest score (42). As for examining the working experience, the duration of working in the current unit had a significant relationship with the majority of areas of safety culture, so that increasing working experience was an effective factor in increasing the patient safety culture. Also, the findings showed that increasing the number of the working hours per week resulted in reduction of the amount of safety culture. Increasing the number of weekly work hours causes fatigue which in turn increases the amount of errors. Researches show that among the various dimensions of the fatigue, the two dimensions, mainly the mental fatigue and fatigue resulting from decreased activity, are related to the occurrence of nursing errors (44).Respecting examining the viewpoints and samples of studying in patient safety, maternity and nursing departments were considered as the most important parts, in addition, official staff were the most important occupational category in enhancing the safety culture, who have attempted to better implement the cure performances due to more work experience. However, different ranges of the age group did not affect in patient safety culture increasing. Researches have shown that a positive safety culture directs health care staff's precautionary behaviors toward looking at patient safety as one of their highest priorities; in this regard an organization with the safety culture in case of accidents with employees is fair and explicit. (17).

\section{Conclusion}

Patient safety is critical to being a strategic priority for statement and health system executives. Changing the hospitals in order to improve the patient safety culture requires a major evolution and it should be supported via changing values, behaviors and beliefs of the staff, and also, it should be considered the aids of the senior hospital managers. According to the results of this study, it was determined that the patient safety culture, in all dimensions, has enjoyed particular importance in order to improve the delivery of services to hospitalized patients. It is proposed that regarding the importance of the senior manager's roles, especially nursing managers of hospitals, in promoting the patient safety culture, policies and programs are designed and employed to create the substructure of the patient safety culture in hospitals.

\section{Acknowledgements}

This study is part of the research approved by the Research Council of Islamic Azad University of Rasht (ethics code: IR.IAU.RASHT.REC.1395.30). We would like to thank the research vicechancellor for financial support, as well as all the nurses for their contributions to this study. 


\section{References}

1- Smites M, Christiaans-Dingelhoff I, Wagner C, Wal G, Groenewegen PP. The psychometric properties of the 'Hospital survey on Patient safety culture in Dutch hospitals. BMC Health Serv Res 2008; 8(1): 230-238.

2- Westat R, Sorra J, Famolaro T, Dyer MN, Khanna K, Nelson D. Hospital survey on patient safety culture: 2010 User Comparative Database Report. Agency for Healthcare Research and Quality US Department of Health and Human Services. 2010 Mar.

3- Kim J, An K, Kim MK, Yoon SH. Nurses'Perception of error reporting and patient safety culture in Korea. West J Nurs Res 2007; 29(7):827-844.

4- Bodur S, Filiz E. Validity and reliability of Turkish version of "Hospital Survey on Patient Safety Culture" and perception of patient safety in public hospitals in Turkey. BMC Health Serv Res 2010; 10(28):1-9.

5- Kristensen S, Bartels P. Use of Patient Safety Culture Instruments and Recommendations. European Society for Quality in Healthcare. Office for Quality Indicators.2010, Denmark.

6- Zohar D, Livne Y, Tenne-Gazit O , Admi H, Donchin Y. Healthcare climate: a framework for measuring and improving patient safety. Critl Care Med. 2007; 35(5):1312-17.

7- Schein EH. Organizational culture and leadership.3ndEd. San Francisco, CA: JosseyBass; 2010.

8- Feng X, Bobay K, Weiss M. Patient safety culture in nursing: a dimensional concept analysis. J Adv Nurs 2008; 63(3): 310-19.

9- Allen S, Chiarella M, Homer C. Lessons learned from measuring safety culture: An Australian case study. Midwifery. 2010; 26(5). 497-503.

10- Poley MJ , van der Starre C, van den Bos A, van Dijk M, Tibboel D. Patient safety culture in a Dutch pediatric surgical intensive care unit: an evaluation using the Safety Attitudes Questionnaire. Pediatr Crit Care Med 2011; 12(6):e310.

11-Ginsburg R, Gilin D, Tregunno D,Norton PG, Flemons W, Fleming M. Advancing measurement of patient safety culture. Health Serv Res. 2008; 44(1):205-24.

12- Schutz L, Counte A, Meurer S. Development of apatient safety culture measurement tool for ambulatory health care settings: analysis of content validity. Health Care Manage Sci .2007; 10(2): 139-149. 
13- Bodur S, Filiz E. A survey on patient safety culture in primary healthcare services in Turkey. Int J Qual Health Care .2009; 21(5): 348-355.

14-. Zwart DL, Langelaan M , van de Vooren RC, Kuyvenhoven MM, Kalkman CJ, Verheij TJ, et al. Patient safety culture measurement in general practice. Clinimetric properties of 'SCOPE'. BMC Fam Pract. 2011; 12(117):1-7.

15- Webair HH, Al-Assani SS, Al-Haddad RH, Al-Shaeeb WH, Bin Selm MA, Alyamani AS. Assessment of patient safety culture in primary care setting, Al-Mukala, Yemen.BMC Fam Pract. 2015; 16(136):1-9.

16- El-Jardali F, Jaafar M, Dimassi H, Jamal D, Hamdan R. The current state of patient safety culture in Lebanese hospitals: a study at baseline. Int $\mathrm{J}$ Qual Health Care. 2010;22(5):386-95.

17- Nieva V, Sorra J. Safety culture assessment: A tool for improving patient safety in healthcare organizations. Qual Saf Health Care. 2003; 12(2):17-23.

18- Sorra J, Gray L, Streagle S, et al. AHRQ Hospital Survey on Patient Safety Culture: User's Guide. (Prepared by Westat, under Contract No. HHSA290201300003C). AHRQ Publication No. 15-0049-EF (Replaces 04-0041). Rockville, MD: Agency for Healthcare Research and Quality. 2016.

19- Cameron KA, Engel KG, McCarthy DM, Buckley BA, Mercer Kollar LM, Et al. Examining emergency department communication through a staff-based participatory research method: Identifying barriers and solutions to meaningful change. Ann Emerg Med 2010; 56(6):614-22.

20- El-Jardali F, Jaafar M, Dimassi H, Jamal D, Hamdan R. The current state of patient safety culture in Lebanese hospitals: a study at baseline. Int J Qual Health Care. 2010; 22(5):386-95.

21-Moussavi F, Moghri J, Gholizadeh Y, Karami A, Najjari S, Mehmandust R, et al. Assessment of patient safety culture among personnel in the hospitals associated with Islamic Azad University in Tehran in 2013. Electron Physician. 2013; 5(3):664-71.

22- Van Noord I, de Bruijne MC, Twisk JW. The relationship between patient safety culture and the implementation of organizational patient safety defences at emergency departments. Int J Qual Health Care. 2010; 22(3):162-9.

23- Chen I C, Li H H. Measuring patient safety culture in Taiwan using the Hospital Survey on Patient Safety Culture (HSOPSC). BMC Health Serv Res.2010;10(1):152.

24- Chakravarty A. A survey of attitude of frontline clinicians and nurses towards adverse events. Med J Armed Forces India. 2013; 69(4):335-40. 
25- Kocher KE, Shane SA,Venkatesh AK, Aronsky D, Asplin BR, Rathlev NK.Interventions to safeguard system effectiveness during periods of emergency department crowding. Acad Emerg Med 2011; 18(12):1313-7.

26-Lowthian J , Curtis A , Straney, L , McKimm A , Keogh M , Stripp A. Redesigning emergency patient flow with timely quality care at the Alfred. Emerg Med Australas. $2015 ; 27(1): 35-41$.

27- Mazzocato P, Forsberg, H H, Schwarz U T. Team behaviors in emergency care: a qualitative study using behavior analysis of what makes team work. Scand J Trauma Resusc Emerg Med. 2011; 19(70):1 - 8 .

28- Carbo AR, Tess AV, Roy C, Weingart SN. Developing a high-performance team training framework for internal medicine residents: The ABC'S of teamwork. J Patient Saf. 2011; 7(2):72-6.

29- Committee on Pediatric Emergency Medicine. Patient safety in the pediatric emergency care setting. Pediatrics. 2007 Dec 1;120(6):1367-7

30- Abdi ZH, Maleki MR, Khosravi A. Perceptions of patient safety culture among staff of Selected hospitals affiliated to Tehran University of Medical Sciences. Payesh 2011; 10(4): 4119.[Persian]

31- Buljac-Samardzic M, van Wijngaarden JD, van Wijk KP, van Exel NJ. Perceptions of team workers in youth care of what makes teamwork effective .Health Soc Care Community. 2011; 19(3): 307-316.

32- Baker DP, Day R, Salas E. Teamwork as an essential component of high-reliability organizations. Health Serv Res.2006; 41(4): 1576-1598.

33- Castner J. Validity and reliability of the brief teamstepps teamwork perceptions questionnaire. J Nurs Meas. 2012; 20(3):186-198.

34- Blegen MA, Sehgal NL, Alldredge BK, Gearhart S, Auerbach AA, Wachter RM. Improving safety culture on adult medical units through multidisciplinary teamwork and communication interventions: the TOPS Project. Qual Saf Health Care. 2010;19(4):346-50.

35- Chiodo A, Wilke R, Bakshi R, Craig A, Duwe D, Hurvitz E. Using Lean principles to manage throughput on an inpatient rehabilitation unit. Am J Phys Med Rehabil. 2012; 91(11):977-983.

36- Mwachofi A, Walston SL, Al-Omar BA. Factors affecting nurses' perceptions of patient safety. Int J Health Care Qual Assur. 2011; 24(4):274-283.

37- Zohar D, Livne Y, Tenne-Gazit O, Admi H, Donchin Y. Healthcare climate: a framework for measuring and improving patient safety. Crit Care Med .2007; 35(5):1312-17.

38- Kim J, An K, Kim MK, Yoon SH. Nurses' perception of error reporting and patient safety culture in Korea. West J Nurs Res. 2007; 29(7):827-844. 
39- McCulloch P, Rathbone J, Catchpole K. Interventions to improve teamwork and communications among healthcare staff. Br J Surg. 2011; 98(4): 469-479.

40- Mercer MP, Hernandez-Boussard T, Mahadevan SV, Strehlow MC. Physician identification and patient satisfaction in the emergency department: Are they related? J Emerg Med. 2014; 46(5):711-8.

41- Rideout D. 'Just Culture'encourages error reporting, improves patient safety. OR Manager 2013; 29(7):13-15

42- Bodur S, Filiz E. Validity and reliability of Turkish version of "Hospital Survey on Patient Safety Culture" and perception of patient safety in public hospitals in Turkey. BMC Health Serv Res 2010; 10(28):1-9.

43- Stone PW, Money-Kane C, Larson EL, Horan T, Glance LG, Zwanziger J, et al. Nurse working conditions and patient safety outcomes. Med Care 2007; 45(6):571-578.

\section{Bibliographic information of this paper for citing:}

Majidi SA, Alizadeh SH, kouchakzadeh Talami S, et al. Patient safety culture from the viewpoint of nurses: a cross-sectional study in 2016.

J Res Dev Nurs Midw, 2019; 16(2): 71-83.

Copyright @ 2019, Seyed Ali Majidi, Shiva Alizadeh, Sobhaneh kouchakzadeh Talami, Hamideh Safarmohammadi, Ehsan Kazemnezhad Leily, Monika Motagi , Mehdi Barzegar. 